\title{
Flipping the classroom and turning the grades - a solution to teach unbeloved phase diagrams to engineering students
}

\section{Pfennig, Anja}

HTW Berlin, Univerity of Applied Sciences HTW Berlin, Wilhelminenhofstr. 75A, 12459 Berlin, Germany

\begin{abstract}
Phase diagrams may simply be described as alloying maps in material science. However, the required thermodynamic background knowledge should be high level and understanding of the cooling procedure of metal melts as well as microstructure of metal alloys is challenging. Common teaching material presents results, but not how to get there and leaves frustrated first year engineering students behind. Knowledge on "how to read" phase diagrams is expected from teachers in advanced courses, but requirements are seldoml met by the students. Teaching phase diagrams in an "inverted classroom" scenario is a method to let the students study the science on their own and then take the time to discuss their questions and do extended hands on lectures or exercises in class. Implementing the inverted classroom approach has been proven to be successful in terms of learning outcome, problem solving skills related to phase diagrams and in improving grades. Although the time of preparation is raised by a factor of approximately 4 for 2 four-hour classroom sessions, the positive and sustainable learning outcomes make fun to teach and worth the effort.
\end{abstract}

Keywords: phase diaram, lecture films, peer to peer, inverted classroom, flipped classroom, blended learning, first year students. 


\section{Teaching concept: "inverted classroom"}

The material science course for first year mechanical engineering students at HTW Berlin is taught via the "design-led" teaching approach: Ashby et al. (2013), exceLlus (2016), (Pfennig 2016-1, Pfennig 2016-2). In contrast to the conventional "science-led" teaching approach which begins with the physics and chemistry of materials, progressing from the atomistic through the microstructure to the macroscopic properties: the design led approach starts with the needs of the design and then explains why and how properties can be influenced and changed.

Teaching via "inverted classroom" scenarios, Pfennig (2016), is a method to let the students study the science on their own and then take time to discuss their questions and do extended hands on lectures or exercises in class. Berret (2012), Brame (2015), Fischer and Spannagel (2012), Braun et al. (2012) proved this teaching method successful to gain student's attention, thus acquire good exam results. Lecture films: OLP (2016), Pfennig (2016-2) were chosen as one of the main resources students acquired their scientific background from besides a variety of teaching material such as micromodule lectures, worksheets and worked solution, mind maps, glossaries, memory sheets, online tests and web-basedtrainings wbt: Pfennig und Böge (2015), Pfennig (2016-1). An important issue of the concept is, that the students were able to study individually, self-directed, locationindependent, asynchronously and according to their individual tempo. In class there is time to discuss problems, work on exercises and engineering related problems in small groups, share difficulties and thoughts with neighbours and classmates.

In first year material science in mechanical engineering the following themes are taught via "inverted classroom" scenarios indicating improvement of learning skills and grades compared to front classroom teaching methods (Pfennig 2016, Pfennig and Hadwiger 2016, Pfennig and Böge 2015):

- Defects in crystals

- Heat treatment

- Introducing microstructure and materials families

- Phase diagrams and the Iron-Carbon phase diagram

- Hardening mechanism

- Nomenclature of materials

- Steel qualities

- Fibre reinforced polymers

- Introduction to polymers

Still, we believe a mixture of teaching methods prevents boredom, predictability and preferences of certain learning types. Surprising raises grades and learning outcome. 


\section{Introducing phase diagrams: home assignment and contact time}

Phase diagrams and how to interpret, read and transfer their knowledge onto real microstructures of materials seems to be an awful hassle for first year students. Due to the curricula, this theme has to be taught in first year engineering studies at HTW Berlin. Phase diagrams may simply be described as alloying maps in material science. However, the required thermodynamic background knowledge is high level and understanding the cooling procedure of metal melts as well as microstructure of metal alloys is challenging. Common teaching material presents results, but not how to get there and leaves frustrated first year engineering students behind. Knowledge on "how to read" phase diagrams is expected from teachers in advanced courses, but requirements are seldom met by the students. Therefore, it is much more successful, to engage the students into practical work and team assignments where they have to use their knowledge rather than listening, copying notes and memorizing during class.

Self-studying was assigned via "moodle". The 4-hour lecture on phase diagrams was filmed in SS2015 and cut into 9 videos with distinct headlines, so that each student could easily navigate to understand how to read phase diagrams (figure 1).
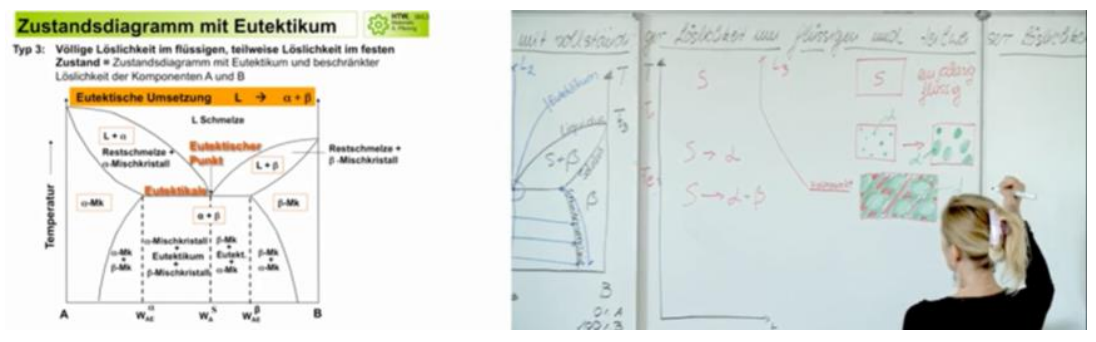

Figure 1. Lecture video: phase diagrams (11 lecture films) (2:35 hours), (https://www.youtube.com/playlist?list=PLUOlZMSZYz5zha5EbwAKrQ8w8W65ST3fN)

In class the open-source software "invote" (invote, 2016) was used for peer reviewing (Simon et al., 2010, Pfennig 2015, Pfennig 2016), to obtain an overview of the student`s knowledge. Questions were answered and important issues explained individually. Students were divided into groups of 4.12 assignments of different levels were categorized into: 1 .) pass the class, 2.) pass with $\mathrm{C}$ or $\mathrm{B}, 3$.) pass with $\mathrm{A}$ or even better. The students were asked to choose as they felt comfortable. The advantage of teaching small groups was that individual problems were solved and questions of different levels were answered by speaking to the students face to face and meeting her or his needs. Each group recieved colored cards (green: everything is going well, yellow: we need some guidance, red: urgent 
question) so that the lecturer could set priorities on which group to work with without disturbing other groups.

\section{Assessment of students learning outcome}

A compulsory test had to be taken via "moodle" at the end of the following week and results showed clearly that students had a much better understanding how to work practically with phase diagrams and related problems compared to results of the end of term exam the previous semester. $45 \%$ of the students scored very good or excellent in winter semester 2015/16 and even 70\% scored very good or excellent in SS 2016 (figure 2).

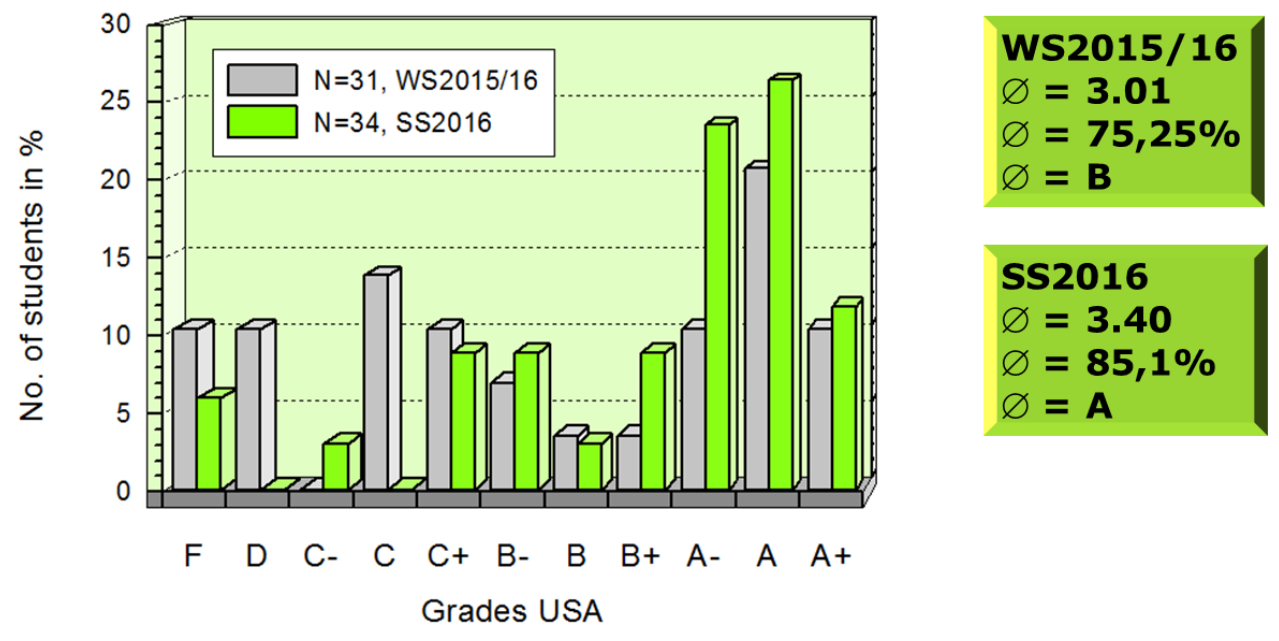

Figure 2: Results of compulsory online exam on phase diagrams.

In the final exams students scored $43 \%$ of the phase diagram related problem in SS2015 with no inverted classroom scenario applied (figure 3, left) and 68\% in SS2015/16 with phase diagrams being taught by using the inverted classroom approach (figure 3 , right). 

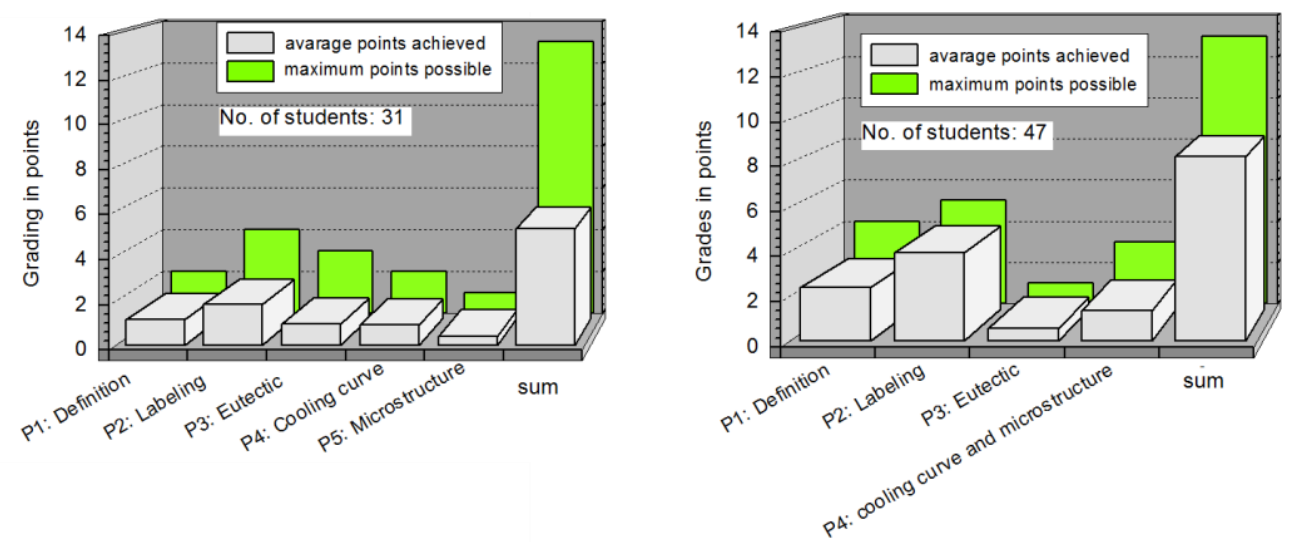

Figure 3. Results of compulsory online exam on phase diagrams, left SS2015, right WS15/16

\section{Evaluation of lecture videos}

Overall students rated the class as successful (68-73\% rated good or excellent), both, in terms of learning output and good study atmosphere in class. Most students rate the repeatability of the film lecture units beneficial. $80 \%$ state that videos of lectures may completely replace lectures in presence; only $12 \%$ believed that their study progress will only be enhanced in class. None of the lecture films was defined as best or worst with students watching one to all lecture films. Lecture film "Introduction" and "phase diagram with complete solubility" were defined as "easyto follow". All lecture videos appeared equally beneficial regarding the individual learning process. This represents the diversity of the class and shows that none of the subthemes is liked most. It is remarkable that many students (137) clicked on the entire lecture film (2 hours and $35 \mathrm{~min}$.) and watched an average of $20 \mathrm{~min}$. (ca. 15\%) before deciding to go with smaller units.

Some students criticised that during some film minutes board and viewgraph could not be seen together, so that they had difficulties bringing the lecture in order (although viewgraphs were downloaded before the assignment). A good suggestion was to focus on the writing more than on the lecturer during filming. The time slot for phase diagram lecture film preparation was asked to be 14 days and not as is has been here only 7 days.

The author wants to point out that no significant relation between number of clicks and length of the lecture films was analysed (figure 4). The same applies for the time a lecture film was watched as a function of its total length (figure 5). That means that the length of lecture films has no influence on the study behavior of the students. Moreover they decide on their individual needs and interest when watching and studying videos. 


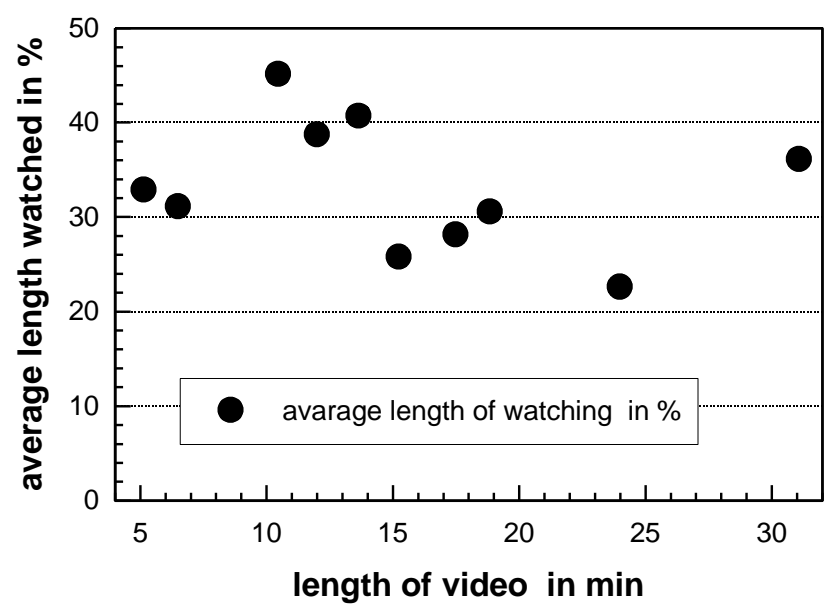

Figure. 4: Average time in \% of students watching lecture films in WS2015/16.

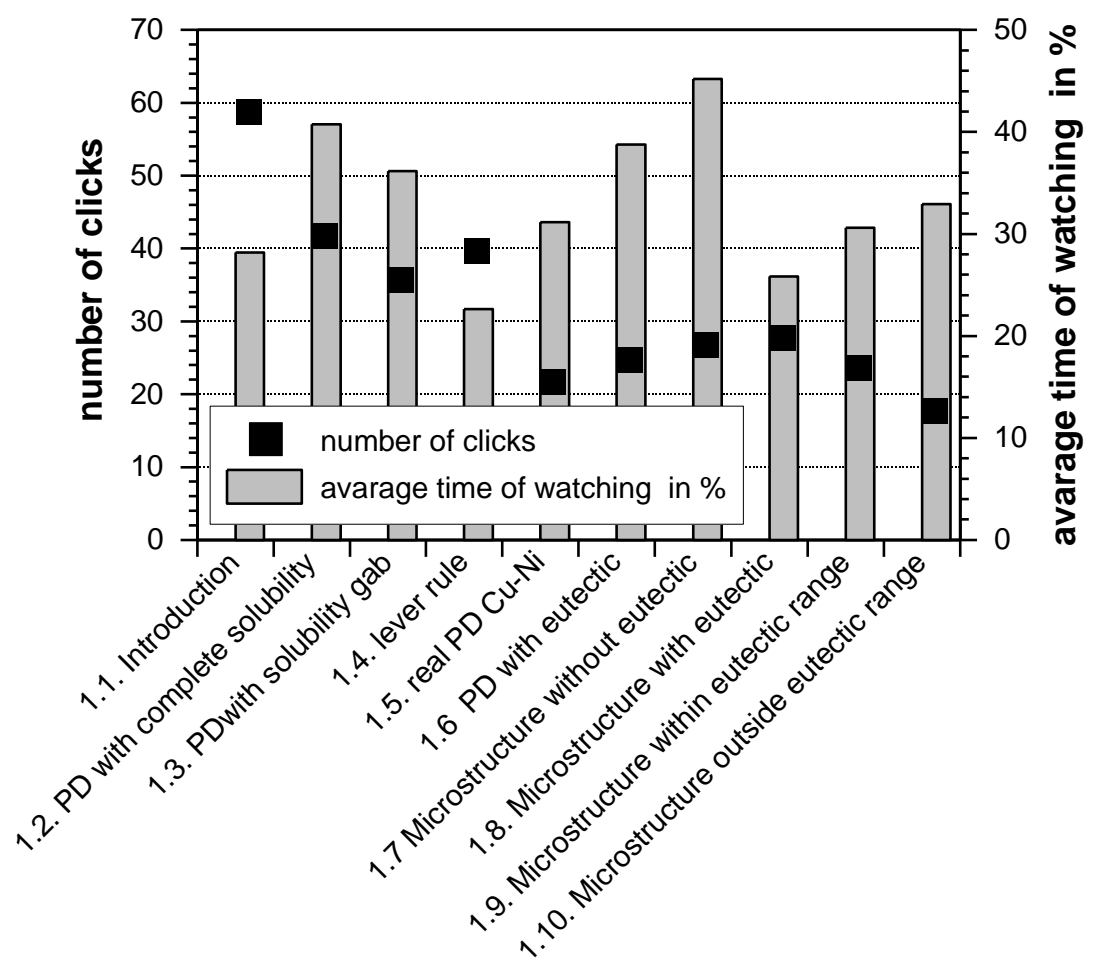

Figure. 5: Clicks and average time in \% of students watching lecture films as a function of lecture film unit in WS2015/16, inverted classroom scenario. 
All in all, the lecture concept ,inverting the classroom” with self-studying based on videos of class lectures was rated positively. Students were eager to work on problem solving in small groups and present their results to the class. $70 \%$ of the students brought notes on the lecture films into class showing their serious study period at home helping with the hands on problems in class. Depending on their state of learning students individually chose lecture videos, number of repeats of the same video and the length of time they kept watching continuously.

\section{Feedback on the "inverted classroom" concept - drawing a conclusion}

Lecture videos as main source of the "inverted classroom concept" are independently reusable once generated and provided. They apply well in the nowadays student's way of achieving skills. The independence of time and place of the individual lecture in combination with the possibility to repeat whole lectures as well as small parts helps to meet the individual learning velocity of the students. During self-studying students were very motivated to learn, then share their knowledge helping others and contributing to solving problems in class. The pleasant atmosphere in class enabled students to apply their knowledge solving material science problems. Small groups allow for individual explanations and personal contact to students. If both students, who are producing lecture films as well as those learning through them, are given more responsibility for their learning progress critical thinking will be encouraged: CSU (2015), Lord (2012); resulting in deeper learning outcomes: Goto and Schneider (2010), Simon et al. (2010).

There is always the chance of losing students who are not willing to study at home will be lost in the long run, first because of lack of background knowledge, second because they are not able to contribute to group or class work or work on assignments independently. Therefore it is always necessary to be prepared for groups that may not be able to work properly in class. Because the assignment was clear, there is no time for lecturers to let them catch up in class. But, because peers are sitting next to them our experience was that these students prepared themselves very well after the contact time and achieved good grades. In general, the same number of students (35 out of 44) visited the classes regularly compared with the courses taught the traditional way. Time spent studying before class (approx. 4-5h) in the inverted classroom environment equals up to the time estimated to study after class taught in-front to understand and get good grades according to the students.

The method of "inverting the classroom" was assessed as beneficial in terms of student grades, concentration and attentiveness as well as joy of studying. Students took over responsibility for their own learning process and generally achieved better grades than those taught in "front classroom" scenarios. 


\section{References}

Ashby, M., Shercliff, H., Cebon, D.: Materials Engineering, Science, Processing and Design, 2013: ISBN-13: 978-0080994345, 2013: ISBN-10: 0080994342, Pub date: Oct $02,2013\left(3^{\text {rd }}\right.$ edition).

Berrett, D.: How 'flipping' the classroom can improve the traditional lecture, The Cronicle of Higher Education (2012).

Brame, C.J.: Flipping the Classroom, http://cft.vanderbilt.edu/files/Flipping-theclassroom.pdf, call: 09/2015.

Braun, I. et al., Inverted Classroom an der Hochschule Karlsruhe - ein nicht quantisierter Flip, Beitrag zu „Das Inverted Classroom Model: Begleitband zur ersten deutschen ICM-Konferenz"“, Jürgen Handke, Alexander Sperl (Hrsg.), erschienen im Oldenbourg Verlag, 2012.

Colorado State University, Using Peer Teaching in the Classroom, (2015), http://teaching.colostate.edu/tips/tip.cfm?tipid=180.

Educause Learning initiative, THINGS YOU SHOULD KNOW ABOUT... ${ }^{\text {TM }}$ FLIPPED CLASSROOMS, https://net.educause.edu/ir/library/pdf/eli7081.pdf, call: 01/2016.

Fischer, $\mathrm{M}$ und Spannagel, C: Lernen mit Vorlesungsvideos in der umgedrehten Mathematikvorlesung, in Desel, J., Haake, J.M. und Spannagel, C. (Hrsg.), DELFI 2012, Die 10. E-Learning Fachtagung Informatik der Gesellschaft für Informatik e.V., S. 225-236, Bonn: Köllen Druck + Verlag, Copyright @ Gesellschaft für Informatik.

Goto, K. \& Schneider, J., Learning through teaching: Challenges and opportunities in facilitating student learning in food science and nutrition by using the interteaching approach. Journal of Food Science Education 9(1) (2010) 31-35.

http://invote.de/, call 01/2016.

Lord, T., 101 reasons for using cooperative learning in biology teaching. The American Biology Teacher 63(1) (2012) 30-38.

Online Lehre Plus / external fund: Berliner Qualitätsoffensive für die Lehre/ https://www.berlin.de/sen/wissenschaft/wissenschaftspolitik/finanzierung/vereinbarung _berliner_qualitaetsoffensive_fur_die_lehre_2012_bis_2016.pdf.

Qualitätspakt Lehre - Teil-Projekt ,excelLuS“ HTW-Berlin: "Studieren an der HTW Berlin - exzellente Lehre und hervorragender Service", Förderprogramm "Bund-LänderProgramm für bessere Studienbedingungen und mehr Qualität in der Lehre" des Bundesministeriums für Bildung und Forschung (BMBF) mit Förderkennzeichen: 01 PL 11034 und Förderzeitraum vom 01.11.2011 - 30.06.2016.

Schumann, Prof. Dr. Metallographie. Leipzig: Deutscher Verlag für Grundstoffindustrie GmbH, Leipzig 1991, 1990. 13. Auflage.

Simon, B., Kohanfars, M., Lee, J., Tamayo, K, \& Cutts, Q., Experience report: peer instruction in introductory computing. Proceedings of the 41st ACM Technical Symposium on Computer Science Education (2010) 341-345.

Pfennig, A., Inverting the Classroom in an Introductory Material Science Course, Procedia - Social and Behavioral Sciences 228 (2016) 32-38. 
Pfennig, A. and Hadwiger P., Peer-to-peer lecture films - a successful study concept for a first year laboratory material sci-ence course, Procedia - Social and Behavioral Sciences 228 (2016) 24-31.

Pfennig, A. and Böge, A., A material science course based on a blended learning concept using an interdisciplinary approach at HTW Berlin, "e-Learning'15", 11-12 September 2015, University of Applied Sciences, Berlin, Germany.

Fingerson, L. \& Culley, A., Collaborators in teaching and learning: Undergraduate teaching assistants in the classroom. Teaching Sociology, 29(3) (2001) 299-315.

Cuseo, J.B., Tips for students when forming learning teams: How to collaborate with peers to improve your academic performance. Cooperative Learning and College Teaching 7(3) (1992) 11-16. 